\title{
Atualidade Teológica
}

Revista do Departamento de Teologia da PUC-Rio

Ano XVII, no ${ }^{\circ}$ 45, setembro/dezembro 2013 
A898

Atualidade teológica: Revista do Departamento de Teologia da PUC-Rio. - Ano XVII, n. 45 (set./dez. 2013), - Rio de Janeiro: PUC-Rio, Dep. de Teologia/Letra Capital, 2013. 235 p.: il.; $16 \times 23 \mathrm{~cm}$.

Sequência de: Revista Atualidade Teológica - Ano XVII, Fascículo no 44 Continua com: Revista Atualidade Teológica - Ano XVII, Fascículo nº 45 Inclui bibliografia e Sumário ISSN 1676-3742

1. Teologia - Periódicos. I. Pontifícia Universidade Católica do Rio de Janeiro. Departamento de Teologia. II. Título: Revista do Departamento de Teologia da PUC-Rio.

13-07974 CDD: 230

CDU: $2-12$

Revisão Final

Isidoro Mazzarolo

Leonardo Agostini Fernandes

Lúcia Pedrosa de Pádua

Maria Teresa de Freitas Cardoso

Mario de França Miranda

\section{EDitoraÇão Eletrônica}

Francisco Macedo

Produção Gráfica

Letra Capital Editora 


\section{Atualidade Teológica \\ Revista do Departamento de Teologia Pontifícia Universidade Católica do Rio de Janeiro}

\section{Editora}

Maria Teresa de Freitas Cardoso - PUC-Rio, Rio de Janeiro, RJ - Brasil

\section{Conselho Editorial}

Isidoro Mazzarolo - PUC-Rio, Rio de Janeiro, RJ - Brasil

Leonardo Agostini Fernandes - PUC-Rio, Rio de Janeiro, RJ - Brasil

Lúcia Pedrosa de Pádua - PUC-Rio, Rio de Janeiro, RJ-Brasil

Luís Corrêa Lima - PUC-Rio, Rio de Janeiro, RJ-Brasil

Mario de França Miranda-PUC-Rio, Rio de Janeiro, RJ-Brasil

\section{Conselho Científico/Consultivo}

Abimar Oliveira de Moraes - PUC-Rio, Rio de Janeiro, RJ-Brasil

Alfonso Garcia Rubio - PUC-Rio, Rio de Janeiro, RJ-Brasil

Ana Maria L. Tepedino - PUC-Rio, Rio de Janeiro, RJ-Brasil

Antonio José de Almeida - PUCPR, Curitiba, PR - Brasil

Cecilia Avenatti de Palumbo - Universidad Católica Argentina - Argentina

Cesar Kuzma - PUC-Rio, Rio de Janeiro, RJ-Brasil

Clodovis Boff - PUCPR, Curitiba, PR - Brasil

Djalma Rodrigues de Andrade - PUC-Rio, Rio de Janeiro, RJ-Brasil

Érico Hammes - PUCRS, Rio Grande do Sul, RS - Brasil

Florentino Garcia-Martinez - Katholieke Universiteit, Leuven - Belgium

Geraldo Dondici Vieira - PUC-Rio, Rio de Janeiro, RJ-Brasil

Ilaria Morali-PUG, Roma - Itália

Jenura Clotilde Boff-PUC-Rio, Rio de Janeiro, RJ-Brasil

Johan Konings - FAJE, Belo Horizonte, BH-Brasil

Lúcia Weiller-ESTEF, Porto Alegre, RS-Brasil

Maria Clara Lucchetti Bingemer - PUC-Rio, Rio de Janeiro, RJ-Brasil

Maria de Lourdes Corrêa Lima - PUC-Rio, Rio de Janeiro, RJ-Brasil

Matthias Grenzer - PUCSP, São Paulo, SP-Brasil

Olga Consuelo Vélez - Pontificia Universidad Javeriana de Bogotá - Columbia

Paulo Cezar Costa - PUC-Rio, Rio de Janeiro, RJ - Brasil

Paulo Fernando de Andrade - PUC-Rio, Rio de Janeiro, RJ-Brasil

Sergio Sebastianel-PUG-Roma - Itália

Sinivaldo Tavares - FAJE, Belo Horizonte, BH-Brasil

Tereza Maria Pompéia Cavalcanti-PUC-Rio, Rio de Janeiro, RJ-Brasil

Vitor Galdino Feller - ITESC, Florianópolis, SC - Brasil 


\section{Informações Gerais}

Atualidade Teológica é um periódico quadrimestral do Departamento de Teologia da PUC-Rio. Editou seu primeiro número em 1997, tendo completado 15 anos de publicação regular em 2012. Difunde o seu conteúdo de forma impressa (com uma tiragem de 500 exemplares), mas também está disponível on line. ATeo é o titulo abreviado da Revista, usado para efeito de citação em referências bibliográficas, notas de rodapé e legendas bibliográficas.

A Revista é um espaço acadêmico-científico no qual são divulgados trabalhos originais e inéditos em temas teológicos atuais, tanto da área bíblica como da área sistemático-pastoral. Oferece a pesquisadores, brasileiros e estrangeiros, a possibilidade de divulgarem os avanços e os resultados de suas pesquisas nessas áreas. O efeito é um olhar multiforme, aberto e atual da produção bíblico-teológica.

A publicação completa ou parcial do conteúdo só pode ser feita mediante a prévia autorização dos autores e do Conselho Editorial.

\section{Missão e Objetivos}

Atualidade Teológica é um serviço à reflexão teológica cristã e ao discernimento eclesial. Contribui para o desenvolvimento e atualização dos estudos teológicos nas áreas bíblica e sistemático-pastoral, em abertura dialógica à cultura, às ciências e às religiões. Difunde os seus resultados e mostra os rumos da teologia ao seu público leitor, abrindo-se assim ao debate teológico nas igrejas e na sociedade.

\section{Normas de Submissão e Avaliação}

Os artigos, as comunicações e as resenhas propostos para a publicação devem ser originais e inéditos. São captados entre o corpo docente e o corpo discente dos Programas de Pós-Graduação em Teologia, dentro e fora do território nacional. Devem seguir as normas da ABNT e da Revista, ser encaminhados e submetidos à aprovação do Conselho Editorial.

A avaliação das contribuições é realizada entre os membros do Conselho Científico/Consultivo e pareceristas externos. Adota-se o processo de avaliação por pares (peer review), com sistema duplo de revisão anônima (blind review), mantendo-se o sigilo dos nomes dos avaliadores e dos autores. 


\section{General Information}

Atualidade Teológica is a four-monthly periodical of the Department of Theology of PUC-Rio (the Pontifical Catholic University of Rio de Janeiro). Its first issue was published in 1997, and it completed 15 years of regular publication in 2012. It is published in printed form (with an edition of 500 copies), but it is also available on line. ATeo is the abbreviated journal title, used for purposes of quotation references, footnotes and bibliographic list.

The Periodical is an academic and scientific space in which original and unpublished works on current theological themes are presented, both in the Biblical and in the systematic and pastoral fields. It offers Brazilian and foreign researchers an opportunity to disseminate their progress and the results of their research in these fields. The result is a multifaceted overview of current Biblical-theological work in progress.

Publication of the complete work or part of it requires prior authorization of the authors and of the Editors.

\section{Mission and Objectives}

Atualidade Teológica offers a service to Biblical reflection and ecclesiastical discernment. It contributes to the development and renewal of Christian theological reflection in the Biblical and systematic-pastoral fields, in an open dialog with culture, the sciences and religions. It presents its results and shows the trends of theology to its reading public, thus opening itself to theological debate with the churches and with society.

\section{Norms for Submission and Evaluation}

The articles, communications, and reviews submitted for publication should be original and unpublished. Contributions are invited from faculty and students of Graduate Programs in Theology, both in Brazil and abroad. They should follow the norms of the ABNT and of the Periodical when they are submitted for the approval of the Editors.

The evaluation of contributed articles and reviews is carried out by members of the Scientific Consulting Committee with the help of external referees. The process of peer review with a system of double blind refereeing is used, thus preserving the anonymity of both the referees and the authors. 


\section{ISSN 1676-3742 (Revista impressa)}

ISSN 2237-115X (Revista on line)

http://www.maxwell.lambda.ele.puc-rio.br/rev_teologia.php?strSecao=INDEX

\section{Indexadores e Cadastros em Bancos de Dados}

Latindex - Sistema Regional de Informação em Línea para as Revistas Científicas da América Latina, Caribe, Espanha e Portugal

Sistema Maxwell

\section{Para contato e informações}

Pontifícia Universidade Católica do Rio de Janeiro

Departamento de Teologia / Revista Atualidade Teológica

Rua Marquês de São Vicente, $n^{\circ} .225$

Edifício Cardeal Leme, $11^{\circ}$ andar - Gávea

CEP.: 22451-900 - Rio de Janeiro / RJ - BRASIL

Tels.: 55 (21) 3527-1300 e 3527-1974; Fax.: 55 (21) 3527-1302

E-mail's: atualidadeteologica@puc-rio.br (artigos e comunicações)

marianapernambuco@puc-rio.br (secretaria)

\section{Reitor da PUC-Rio}

Josafá Carlos de Siqueira SJ

\section{Diretor do Departamento de Teologia}

Leonardo Agostini Fernandes

\section{Coordenador de Pós-graduação}

Abimar Oliveira de Moraes

\section{Coordenadora de Graduação}

Lúcia Pedrosa de Pádua

\section{Coordenador da Cultura Religiosa}

João Geraldo Machado Bellocchio

\section{Coordenador da Teologia à Distância}

Isidoro Mazzarolo 


\section{Apresentação}

Neste número da Revista Atualidade Teológica publicamos seis artigos e três comunicações. Seus autores abordam temas diversos, importantes para a teologia. São estudos bíblicos em diferentes abordagens; tópicos da fé, da vida, da liturgia; de diálogo ecumênico; de espiritualidade; de aprofundamento sobre a realidade e seu conhecimento.

O primeiro artigo que apresentamos é de Boris Agustín Nef Ulloa. Nele o autor analisa a estrutura da perícope lucana sobre a Apresentação de Jesus no Templo (Lc 2, 22-30). Trabalha sobre a moldura literária e identifica o seu centro. Faz ver uma utilização de textos veterotestamentários, mas o texto neotestamentário tem sua própria narrativa com seu sentido teológico-cristológico sobre a identidade do Menino.

O segundo artigo, de autoria de Alessandra Serra Viegas e Elizangela Chaves Dias, traz uma abordagem narrativa de Gn 22, sobre o sacrifício que Abraão é chamado a oferecer de seu filho Isaac. Além de mencionar métodos para interpretação e de supor no texto o uso de antigas formas literárias, as autoras ponderam que o leitor do texto bíblico será levado a viver o acontecimento narrado, ou a fazer experiência do sacrifício de Abraão, e a deparar-se com "o Deus que pro-vê e que faz ver".

O terceiro artigo é de Cláudia Andréa Prata Ferreira. Ao procurar uma inspiração no livro bíblico de Rute, preocupa-se com as relações sociais, particularmente com uma legislação e uma prática que tenham em conta os menos favorecidos. A autora observa que a temática se relaciona com outros livros bíblicos e destaca Rute como uma imagem de mulher corajosa, para a construção de um povo com perspectiva universal.

O quarto artigo é de Luís Fernando Ribeiro Santana. Ao aproximar Bíblia e Liturgia, o autor reconhece a presença de Cristo em cada ato litúrgico 
e a dimensão pneumatológica da Palavra no culto, para destacar a Palavra de Deus na celebração litúrgica. Ele não só acentuará que a Liturgia é um lugar privilegiado da Palavra de Deus, mas valorizará a possibilidade de "orar" e "celebrar" a Palavra de Deus na Liturgia.

O quinto artigo é de Renato da Silveira Borges Neto. Ele aborda o tema do primado petrino e investiga o diálogo ecumênico em alguns de seus resultados e comentários. Procura vislumbrar pistas para novas perspectivas e sugere que se possam esperar novos passos com o Papa Francisco. O tema do primado comporta dificuldades no diálogo ecumênico, suscita o interesse, e esperamos venha a prosseguir com novos aprofundamentos e desdobramentos.

O sexto artigo, de cunho mais filosófico, é de Carlos Sierra Lechuga. Em vista de uma aproximação da realidade, o autor pressupõe que, ao estudar o real, espera-se que ele seja real; mas o autor quer mostrar que a realidade é gradativa e que é preciso integrar os graus do saber com os da realidade. Ele faz um aprofundamento desse tema. Lembrará que a realidade se dá de modos distintos na ciência e na religião e afirmará com J. Maritain, que somente distinguindo poderemos unir.

A primeira comunicação que apresentamos é de Marco Bartoli, para desvendar "o segredo do Francisco", iniciando-se com a escolha do nome do papa atual. O nome foi escolhido certamente por causa de uma ideia. Bartoli reporta-se, então, a alguns passos importantes da vida de Francisco de Assis, em sua procura de liberdade. Chega à sua aproximação dos pobres e à contemplação do Crucifixo. Descobre-se o segredo de Francisco de Assis na sua experiência de encontro com os outros.

A segunda comunicação é de Dom Paulo Cezar Costa. Discorre sobre a Divina Monarquia em São Basílio Magno. Mostra a conjugação das três hypóstasis com o monoteísmo cristão. Descreve o que é próprio do Pai, do Filho e do Espírito Santo; tem em vista, além da unidade de substância, o relacionamento entre eles. $\mathrm{O}$ autor precisa que "tudo provém do Pai, pelo Filho ao Espírito", destacando que do Pai tudo procede e para Ele tudo se dirige.

A terceira comunicação é de Angela Cristina Germine Pinto Caldeira. Aborda a ressurreição de Jesus tendo em vista a reflexão de Walter Kasper. Primeiro a autora considera a ressurreição de Jesus como fundamento da confissão cristológica. Fala de fundamentos e de reflexões teológicas sobre essa fé na ressurreição e considera a contribuição de W. Kasper, vendo na ressurreição a ação escatológica de Deus, a exaltação de Jesus e a salvação cristã. 
Compartilhamos, desse modo, com os leitores, o estudo bíblico e teológico-sistemático dos que escreveram os textos aqui publicados. O estudo mais filosófico, também incluído, possa aguçar nosso questionamento sobre nosso modo próprio de conhecer e propiciar uma consideração interdisciplinar.

Como de costume, comunicamos ainda nesta publicação: pesquisas realizadas no Departamento de Teologia da PUC-Rio (desta vez relacionamos as do PIBIC); livros adquiridos; a lista de nossas permutas; o índice das publicações do ano.

Que se comunique a todos nosso entusiasmo, ao buscarmos contribuir na missão do Departamento de Teologia da PUC-Rio, que alcançou seus quarenta e cinco anos de vida. Que a lembrança do Pe Antonius Benko, seu primeiro diretor, que partiu para a morada eterna no dia 24 de novembro passado, seja para nós incentivo, de modo que convidamos os leitores a prosseguirmos juntos no diálogo da teologia.

Rio de Janeiro, 12 de dezembro de 2013.

Maria Teresa de Freitas Cardoso Editora 


\section{Sumário}

Ano XVII, $n^{\circ} .45$, setembro/dezembro 2013

ISSN 1676-3742

\section{Artigos}

Análise da estrutura de Lc 2,22-39 e a utilização das Escrituras

Veterotestamentárias em sua moldura literária (vv.22-24.39)

Analysis of the structure of Luke 2,22-39 and the utilization

of the veterotestamentary Scriptures in its frame (vv.22-24.39)

pág.463

Boris Agustín Nef Ulloa

O Deus que pro-vê e que faz ver: uma abordagem

narrativa de Gênesis 22

The God who sees before and makes to see: a narrative

approach of Genesis 22

pág.478

Alessandra Serra Viegas e Elizangela Chaves Dias

O Livro de Rute: uma leitura sobre o discurso e as relações de poder

The Book of Ruth: a reading about discourse and power relations. pág.496

Cláudia Andréa Prata Ferreira

Bíblia e Liturgia

Bible and Liturgy.

Luiz Fernando Ribeiro Santana

Primado Petrino: posições, exercício, perspectivas

Petrine primacy: positions, exercise, perspectives. pág.531

Renato da Silveira Borges Neto

Asir gradualmente la realidad: para un principio de correspondencia ontológico-epistemológico

Grasping gradually the reality: towards an

epistemological-ontological correspondence principle pág.553

Carlos Sierra Lechuga 


\section{Comunicação}

O segredo de Francisco

Francis' secret. pág. 575

Marco Bartoli

A divina monarquia em Basílio Magno

The divine monarchy in Basil the Great pág. 588

Dom Paulo Cezar Costa

A ressurreição de Jesus: uma abordagem a partir da reflexão de Walter Kasper

The resurrection of Jesus: an approach from the reflection of Walter Kasper.... .pág.596 Angela Cristina Germine Pinto Caldeira

\section{Resenha}

Orientações para o uso do Novo Testamento Grego. pág.613 Antônio Renato Gusso

Iniciação Científica. .pág.621

Livros Adquiridos pág. 635

Livros Recebidos .pág.639

Revistas Permutadas pág. 645

Normas para Publicação .pág.651

Publicações (desde 1997) pág. 657

Ficha para Assinatura pág.681

O conteúdo das contribuições é de inteira responsabilidade de seus autores. 